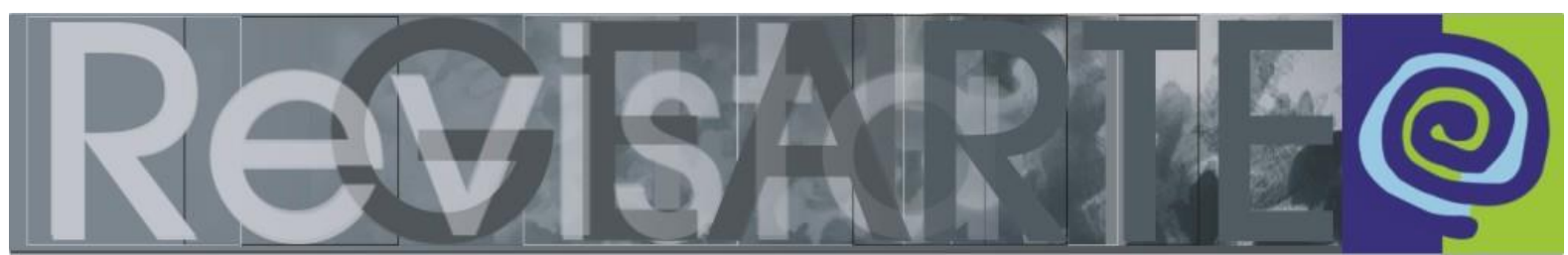

e-ISSN 2357-9854

\title{
O Ensino da Arte como espaço para a reflexão ética. Enfrentar o problema do mal através de uma experiência em sala de aula: Branca de Neve e os predadores internos/externos da psique
}

\author{
Pilar Pérez Camarero (Universidad Autónoma de Madrid - UAM, Madrid/España)
}

\begin{abstract}
RESUMO - O Ensino da Arte como espaço para a reflexão ética. Enfrentar o problema do mal através de uma experiência em sala de aula: Branca de Neve e os predadores internos/externos da psique - Apresento um experimento realizado com estudantes de Educação Artística na Universidade Autónoma de Madrid. Trabalhamos a partir do conto de fadas "Branca de Neve" que nos ajudou a focar em uma questão fundamental no ser humano: o problema do mal. No meu modo de conceber a Educação Artística, os valores são fundamentais e o trabalho de autoconhecimento primordial para desenvolver o trabalho do educador. A partir da arte é possível encontrar um caminho interdisciplinar que nos fala da humanidade e nos faz criaturas socialmente conscientes, da tradição que temos herdamos, do presente e, portanto, do futuro que construímos todos os dias. Visitando salas de aula de diferentes lugares do mundo, tenho observado que um dos principais problemas na educação é a sua utilização como moeda de troca por políticos, e uma das suas maravilhas, que os professores e estudantes podem fazer, criando universos paralelos, no tempo utópico de suas aulas.
\end{abstract}

PALAVRAS CHAVE

Arquétipos. Gênero. Performance. Conto de fadas. Globalização.

RESUMEN - La Educación Artística espacio para la reflexión ética. Afrontar el problema del mal a través de una experiencia en el aula: Blancanieves y los depredadores internos/ externos a la psique - Presento una experiencia realizada con estudiantes de Educación Artística en la Universidad Autónoma de Madrid. Trabajamos a partir del cuento de hadas "Blancanieves" que nos sirvió para enfocar un asunto primordial en lo humano: el problema del mal. En mi forma de concebir la Educación Artística, los valores son fundamentales y el trabajo de autoconocimiento primordial para desarrollar la labor de educador. Desde las artes es posible encontrar un camino interdisciplinar que nos hable de la humanidad y nos haga criaturas concienciadas en lo social que vivimos, de la tradición que hemos heredado y del presente y por lo tanto, el porvenir que construimos día a día. Visitando aulas de diferentes lugares del mundo, he observado que uno de los principales problemas en educación es su utilización como moneda de cambio por los políticos, y una de sus maravillas, lo que los maestros y sus estudiantes pueden hacer, creando universos paralelos, en el tiempo utópico de sus clases.

PALABRAS CLAVE

Arquetipos. Género. Performance. Cuentos de hadas. Mundialización.

\section{Introducción}

En una Educación Artística actual, es urgente, sea donde sea que la ejerzamos, tomar conciencia de lo que significa en un sentido ético ser educadores.

Vivimos un momento histórico complejo, nuestra sociedad avanza a gran velocidad en lo que a tecnología se refiere, pero los problemas que atañen a lo 
humano continúan sin ser resueltos. La escuela es un espacio que apenas cambió en el último siglo y que perpetúa situaciones que ahora afloran con un carácter si cabe más inquietante.

En una sociedad donde los valores se han difuminado en una preeminencia de la eficacia y la competitividad, no es extraño que fenómenos como el acoso escolar proliferen sembrando el dolor y la confusión en el sistema que significa la escuela, que no es otra cosa que un reflejo de la sociedad.

En Europa los radicalismos, la xenofobia y la intransigencia van ganando terreno. En Latinoamérica y concretamente, en Brasil, aun duele la colonización. El pasado no sanó, y en mi país (lo que es peor) la memoria corre el peligro de perderse.

En el curso 2015-2016 realizamos un trabajo de investigación/acción en el aula de Educación Artística y con estudiantes de la carrera de Educación Infantil, en torno al cuento de hadas de "Blancanieves". "Blancanieves" es una historia en donde lo que está en juego es el problema del mal, de la inocencia y los recursos posibles para sortear al depredador. Junto a los estudiantes, y a través de este proyecto educativo pusimos en práctica lo que se puede aprender del cuento. Observamos que las fronteras entre la bondad y la maldad son permeables. Que la conciencia y la decisión marcan la diferencia en un terreno en el que ser responsables de nuestros actos, y compasivos y empáticos con nuestra fragilidad y la ajena, un camino a seguir.

Sabemos que el trabajo individual es clave para producir conciencia y cambios colectivos. No hay que olvidar como algunos de los dictadores más peligrosos, fueron elegidos por sufragio universal, está en cada uno de nosotros apostar por un cambio, que puede ser hecho desde esta pequeña, pero importante escala de la autoconciencia.

\section{El inicio. El problema del mal}

En el año 2015 realizamos en la Universidad Autónoma de Madrid, un seminario sobre el mal en la sociedad contemporánea. Se trató de un seminario 
temático en el que miembros de nuestro grupo de investigación "Cultura, Imaginario y Creación Artística" nos reunimos para reflexionar sobre este complejo asunto.

En mi intervención en ese seminario, Figura 1 - Encarnando el mal el 23 de febrero de 2015 empecé mencionando un sueño reciente: "Soñé -explicaba - que en mi casa había una invasión de soldados, estaban durm iendo, primero no me di cuenta de que eran invasores, pensé que eran mis soldados. Entonces cuando fui a despertarlos y ya los estaba despertando, mis soldados que estaban fueram agazapados, me hicieron ver que los que estaban dentro durmiendo eran el enemigo". Incubé este sueño y eso me hizo ver que para el día de celebración del seminario tenía que ponerme el uniforme posbolonio de rigor y gala ${ }^{1}$, con el abrigo de coronel bajito, con las botas que me dañan las rodillas, en esta fecha de celebración del

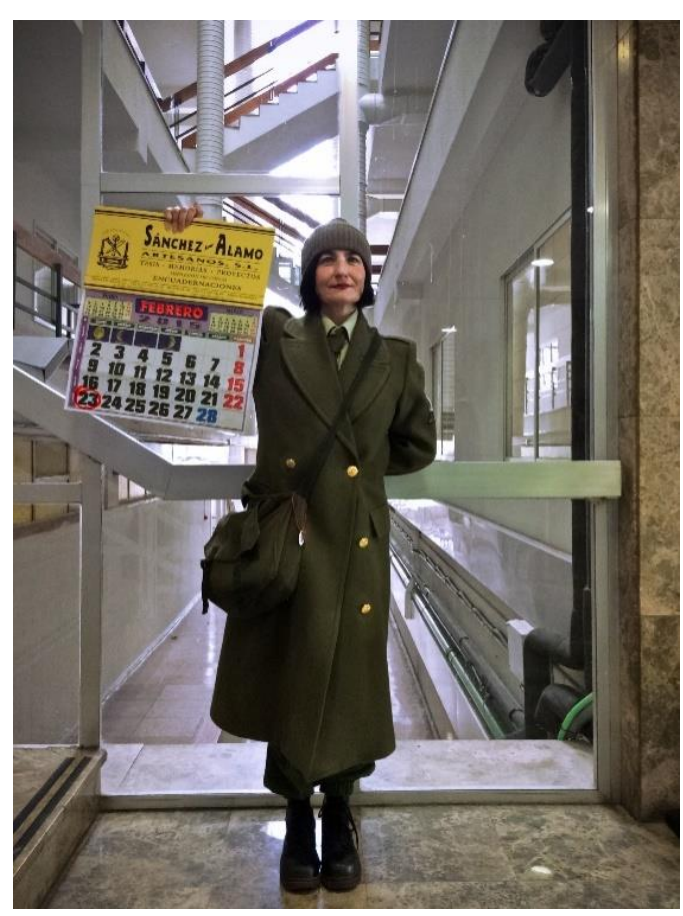

Fuente: Archivo de la autora seminario, 23 de febrero ${ }^{2}$, porque así encarnaría verdaderamente el mal, me decía yo (sintonizando con mi sueño). $Y$ tenía resistencia a hacerloy dormí mal, me costaba asumir y vestir el posbolonio, por la dificultad de integrar esa parte de nuestra historia colectiva.

Mi interés por el problema del mal empezó en el anterior verano, cuando murió mi animal, mi perro Crono, creo que le mataron por la extraña forma en que murió, y que fue un humano quien lo hizo.

1 En ese tiempo y desde octubre de 2011 a octubre de 2015 iba a clase vestida con un uniforme de estética militar, como performance. El uniforme lo llamé posbolonio, relacionándolo con la situación en España tras la reforma europea universitaria de Bolonia, que ha tratado de unificar el sistema educativo, pero que ha sido un fraude en muchos aspectos, encareciendo la educación y propiciando lo contrario de lo que publicitaba.

2 Esta fecha es conmemoración del intento de golpe de estado del 23 de febrero de 1981 en el Congreso de los Diputados, en Madrid. 
En una parte iba percibiendo cada vez con más fuerza algo que ya desde el 2011 cuando comencé a usar el uniforme posbolonio como uniforme performático, iba viviendo. Los atentados de enero de 2015 en París cuando mataron a los dibujantes de Charlie y a los judíos de Vincennes no me extrañaron, en mis viajes a París en los últimos años había sentido una tensión creciente y una militarización en las calles. Después de los atentados, la militarización aumentó: en las escuelas, en los transportes, en todas partes, colonizando la vida cotidiana por los sistemas de seguridad. Y la marcha de judíos en masa, de la que no se habla mucho, y en todo caso dicen que están inmigrando (recuerdo el testimonio de un francés que me dijo "claro es que ellos también son prepotentes, la xenofobia es de siempre, se llaman a sí mismos el pueblo elegido...").

Y luego si voy a mi historia de vida, fui criada por una familia de mujeres a cuyo padre mataron en el inicio de la guerra civil, en 1936. Ellas me educaron en la religión católica desde una visión de polaridad de bien y mal como extremos absolutamente separados, imposibles de unir jamás, y siendo una cuestión de decisión y esfuerzo estar en un polo $o$ en el otro. $Y$ me decían cuando era niña que yo no era suficientemente buena, y que mis "alas" eran incipientes. Y me recuerdo a mi misma mirándome en los escaparates de las tiendas al pasar para ver si por fortuna y de una vez me habían salido las "alas" correctas.

Cuando estaba terminando Bellas Artes, en un proyecto fin de carrera, buscando mi "Verónica", mi "Verdadero retrato"3, me encontré de nuevo con el asunto de las alas. Tomando conciencia de que las alas que me iban más eran las de harpía, las puntiagudas, frente a las beatíficas y algodonosas que no conseguía conciliar en mí (probablemente presintiendo que esas "alas" de mala, podrían protegerme). Cuando te crían con el concepto ideal de lo

Figura 2 - Con alas de mala

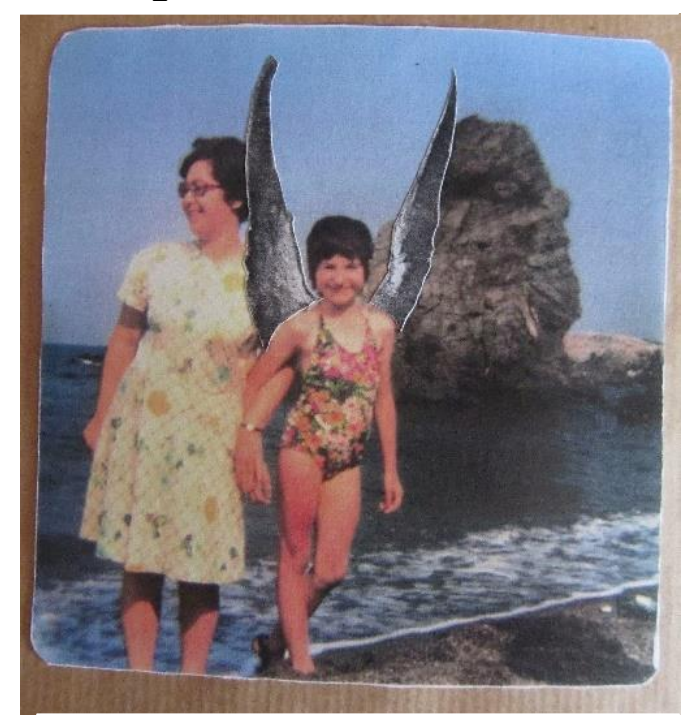

Fuente: Archivo de la autora

3 El Vero- Icono de nuestra tradición judeo cristiana. 
bueno y como niña que eres intentas instalarte en ese lado de la polaridad, esto te provoca una vulnerabilidad muy fuerte frente al depredador interno y externo. $Y$ de una manera intuitiva iba comprendiendo que era muy importante integrar también el otro polo de la dualidad, el de las "alas" de mala4.

Es a partir de esta historia de vida en que siento que tanto el bien como el mal me habitan, y que al final es cierto que es una cuestión de conciencia y de decisión para dónde me incline.

En un sentido conceptual, la posición que mantengo en relación al problema del mal es la de los autores junguianos ${ }^{5}$. También en el boletín de inscripción en el seminario pregunté: “¿Qué es para ti el mal?”, y las interesantes respuestas tenían presente esa polaridad "lo que no es el bien", como si no se pudiera hablar del mal, sin el bien. "La luz, la plenitud... la sombra". "Lo prohibido, la moral". Intuitivamente respuestas que coinciden con planteamientos de los teóricos junguianos.

Según estos autores, el complejo asunto, sobre todo viene de la dificultad de aceptar la polaridad. Si bien los humanos tenemos una tendencia dual, y esto parece que es propio de todas las culturas, pues se manifiesta por doquier el mito dual desde el inicio. Hay el hijo bueno, el hijo malo, la luz, la oscuridad, todo lo que está enfrentado: aquí- allí. Nosotros, frente al otro, el extranjero.

Un poco irreconciliable. El problema según los junguianos es que tenemos tendencia a vivir en un polo negando el otro. $Y$ lo que ocurre es que cuanto más negamos un polo más le afirmamos. Cuanto más estamos en contra de algo, más energía le damos. De esta forma cuanto más tendemos a intentar el bien, más alimentamos de alguna manera el mal.

Lo que más miedo nos da -y el miedo es un asunto importante-es: no vaya a ser que el mal esté dentro de mí y que me destruya. Para no sentirlo dentro lo

4 Fui educada como tantas niñas de mi generación "muy dotada para agradar" (siguiendo a Alice Miller).

5 Seguramente por mi formación como Postgraduada en Psicoanálisis Analítico por la Universidad Ramón Llull de Barcelona. 
proyectamos fuera y toda esa proyección va alimentando un espacio externo, grandilocuente que va encarnando cada vez con más fuerza esa proyección del polo de la sombra y del mal.

La tecnología ha avanzado tanto que basta apretar un botón para ver desaparecer el mundo conocido. El problema ya no es ganar una guerra pues puede significar perderlo todo. Queda esperar que las potencias se controlarán para no apretar ese fatídico botón.

Es decir, la clave es que, si negamos lo que no soportamos internamente, lo vamos a proyectar inflaccionado y haremos que aumente. Cuando le preguntaban a Jung si creía que podía haber una guerra nuclear, él respondía que eso iba a depender de si las personas aguantarían bien o no la tensión de los opuestos dentro de sí. Es decir, finalmente el bien y el mal se trata muchas veces de una cuestión de juicio y somos poco fiables en juicios, erramos todo el tiempo. Por eso decir lo que está bien o mal, bueno o malo es delicado y suele llevar a proyectar el mal fuera.

Si, por ejemplo, me enfado mucho con mi pareja, le llegaré a detestar tanto que me olvidaré de que le quiero (pues me centraré en cómo le odio). La polaridad lleva a lo que los analistas llaman, caminar sobre una sola pierna. Hay un verso del Tao Te King: "El que dice hermoso está creando feo, el que dice bien, está creando mal, resistir determina no resistir, confuso determina simple, alto determina bajo, ruidoso determina silencioso, determinado, determina indeterminado, ahora determina a otrora, así pues el sabio actúa sin acción, dice sin hablar, lleva en sí todas las cosas en busca de la unidad, él produce pero no posee, perfecciona la vida pero no reclama reconocimiento, y porque nunca reclama, nunca sufre pérdida" 6 . Normalmente hacemos lo contrario. Nos ocupamos más de lo que más rechazamos, habría que tenerse cuidado de no rechazar tanto, porque cuanto más lo hacemos más lo incrementamos.

Si pensamos en la historia humana y en el hecho de que hoy la polaridad puede llevar a una destrucción completa, los teóricos para comprenderlo lo que hacen es

6 Segundo verso del Tao Te King de Lao Tsé. 
pensar en nuestros orígenes culturales, nuestra historia judeocristiana. Venimos de unos dioses en el Olimpo que a veces eran "buenos", a veces eran "malos", sin juzgar demasiado el comportamiento humano mientras les rindiéramos las pleitesías debidas. Con Yahvé, la cosa se puso peor, porque ahí la divinidad se convierte en omnisciente y omnipotente, y por otra parte a veces bondadoso y a veces terrible, es decir una contradicción absoluta.

Los junguianos dicen, de una persona que te trata mal no puedes esperar el bien, pero con ello los junguianos olvidan que a veces, el problema es que alguien que te hace bien también puede hacerte mal, y entonces no sabemos distinguir cuándo algo es bueno para nosotros o cuando algo es malo para nosotros?

Yahvé tenía esta dualidad y funcionaba así de una forma muy inconsciente. Dentro de su omnisciencia y omnipotencia parece decir que a veces, cuando quiere, destroza todo y trae las calamidades más grandes, porque sí. En esa época los humanos parecían integrar un Dios que, podía ser muy bueno o muy malo, dependiendo del momento. En Respuesta a Job, Jung reflexiona sobre la relación de Yahvé con Job, un pobre hombre muy fiel, que amaba a Yahvé. Pero Yahvé no se lo creía, parece ser que Satán, le había hecho dudar (Yahvé podía no haber hecho caso a Satán, pero le hizo caso y dejó que le hiciera dudar del fiel Job). Entonces Yahvé comienza a poner a Job a prueba, de una manera brutal, mata su ganado, sus hijos, sus hijas, le enferma y pone al borde de la muerte, le traicionan sus amigos, su esposa, y él sigue fiel. Y Jung dice que, en este libro del Antiguo Testamento, Job se pone por encima de Dios, pues tiene más categoría y catadura moral. Yahvé es más desconsiderado y cruel, e incumple su propia Ley dada en Sinaí, porque quiere, pues para eso es Dios.

Venimos de ahí, de ese desequilibrio entre Yahvé y su súbdito que le había ganado. Jung explica que el desequilibrio se trata de enmendar en la persona de Cristo. Encuentra una figura femenina que es la Virgen que va a parir sin conocer

7 Es el caso de la disonancia cognitiva que producen diferentes tipos de maltrato psicológico, concretamente el que producen personalidades psicopáticas, o perversas, y en general es un tipo de mecanismo de defensa propio de la perversión narcisista. 
varón a Cristo y de esa manera, en Cristo se va a encarnar Dios, que se hace hombre. Pero Jung dice que, si la Virgen no conoce varón, el nacido no parece muy humano. Dice Jung que nuestra tradición religiosa es masculina y poco femenina. Dice también que la actitud que Yahvé tiene con Job es un poco como el marido con la esposa (duda de la fidelidad de ella). Dice Jung que el camino de lo masculino tiende a la perfección, y la perfección no acepta la polaridad, no integra. Lo femenino tiende a la plenitud que sí integra polaridades, y claro no tiende a la perfección. Lo masculino y lo femenino se complementarían entonces, perfección y plenitud. Pero esto no ocurre porque vivimos un sistema unilateralizado en lo masculino.

Cuando Hannah Arendt habla del problema de Eischmann, explica que lo que hizo Eischmann fue hacer muy bien su trabajo, era un perfecto burócrata que había creído la filosofía nazi, y la cumplió. ¿Era malo? Era desde luego eficaz. Encarna el peligro de la perfección. Es muy inquietante porque si uno es perfecto solo queda que todo lo demás sea imperfecto. $\mathrm{Y}$ todo es entonces criticable y tachado de malo. Construye un otro, un enemigo.

La posibilidad de integrar la polaridad internamente es lo que nos puede salvar. La pregunta sería ¿podemos hacer algo, tenemos algún poder frente a lo que pasa? o somos criaturas víctimas de la historia, de tener un Dios tan inconsciente y habernos creado como individuos que buscamos la conciencia (y por lo tanto nos equivocamos todo el rato pues los seres inconscientes como plantas y animales según los junguianos no se pueden equivocar) ¿Cómo somos tan agresivos unos con otros los humanos?

Los junguianos terminan diciendo que este Dios ya hizo un diluvio y otras destrucciones más, y ya lo que quedaría es el Apocalipsis, que es una construcción de una mente pesimista y perfeccionista. Ahora estamos desde luego más cerca que nunca de ese posible desenlace.

Por mi parte soy consciente de que muchas veces me puse en peligro y me acerqué al problema del mal, por ejemplo, durante los años en que hacía la tesis de doctorado, en los trabajos y viajes de campo, en que inconscientemente me introduje 
en entornos que no controlaba y donde había violencia, en España y en Latinoamérica. Cuanto más te acercas más ves que lo que temes es lo que está dentro de ti.

\section{De dónde vengo}

A lo largo de los años en que llevo ejerciendo como profesora de Educación Artística, me ha interesado especialmente vincular mi práctica artística con mi trabajo docente. Esto lo he podido realizar sobre todo gracias a la vertiente performática de mi trabajo creador.

Estoy convencida de que la creación en sí es revolucionaria porque nos ayuda a transformar nuestras vidas, siendo un motor de disfrute y vitalidad, también es un espacio de socialización posible y de compartir goce estético.

Durante el tiempo en que desarrollé la performance longitudinal "Uniforme Posbolonio"8 pude ver cómo los estudiantes de educación, sin formación previa en artes, se sensibilizaban en el activismo implícito en esta performance que tenía como punto fuerte la reiteración iconográfica en el tiempo -vestir un uniforme de estética militar para ir a clase o participar en actos académicos y mantenerlo durante algo más de cuatro años-. Las microperformances que realizamos en ese tiempo, contribuyeron a significar lo que se estaba diciendo de forma calma y a la vez reiterativa con ese uniforme, y en ellas algunos estudiantes pudieron participar activamente (los toques de trompeta para pasar lista, los actos de posbolonización, los cierres e inauguraciones de curso en un gesto simbólico y ritual resistente etc.).

8 Anteriormente las performances "Pato-ente corporativo" (2006-2007) consistente en vestir uniformes de "maestra" junto a mi compañera María Román -profesora como yo en la UAM pero ella de Arte Japonés- uno por cada día de la semana y durante un año. Así como "Bolonia a la española" (20092010) el uniforme previo al posbolonio, también habían producido una reflexión ética que partía de una acción iconográfica y performática. 
Cuando en el año 2015-2016 me encontré con los que serían mis nuevos estudiantes de Educación Artística, acababa de concluir este período de uniforme posbolonio, y estaba muy conmovida por motivos personales en lo que, al problema del mal, el bien y la depredación inter-especie tiene relación.

Todo ello favorecía lo que sería el planteamiento de un viaje colectivo,

Figura 3 - Pasando lista con toques de corneta. Activismo en microperformance dentro de la Performance longitudinal Uniforme Posbolonio. 2011-2015

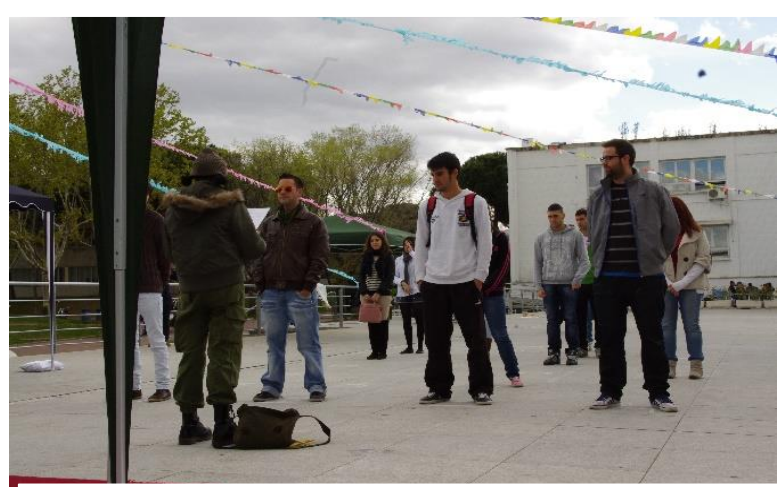

Fuente: Archivo de la autora educativo, performático y vital.

\section{El mal en la Educación Artística. El caso de Blancanieves}

Vamos ahora a lo que pasó en el aula. Durante ese curso 2015-2016 propuse a mis estudiantes de Educación Artística trabajar con el cuento de hadas "Blancanieves", pero a partir de un proceso en que finalmente se llega al cuento. Revisamos diferentes versiones del mismo, de las más antiguas a contemporáneas y en un camino colaborativo y colectivo, desarrollamos un acercamiento a los espacios sombríos de lo humano. El mal, de un concepto ético y moral, ha pasado a ser un aspecto psíquico que puede ser elegido o puede ser diagnosticado como trastorno mental, un trastorno de tipo B para la Sociedad Norteamericana de Psiquiatría. Los cuentos de hadas a lo largo de la historia han acercado a la humanidad a la realidad de sus aspectos más inquietantes, así como a los más luminosos, siendo a la vez, un reducto formativo para instruir en la resiliencia y la firmeza frente a la depredación humana. Hoy en día en que conceptos como el bullying o la psicopatía integrada se aceptan y forman parte del lenguaje cotidiano, planteé una experiencia colaborativa en que el grupo de estudiantes deambuló en torno a la construcción identitaria de los arquetipos y el problema del bien y del mal, produciendo una propuesta liberadora, revolucionaria, germen de conciencia social y educativa. 


\section{Objetivos y Métodos}

Conseguir que el aprendizaje del arte sea un hecho vivo, que los estudiantes integren arte y vida y también arte contemporáneo, es decir, que comprendan la creación actual como parte de sus vidas, y no el arte sólo como un fenómeno museístico. En este sentido compartir mi experiencia como artista y docente (esta doble identidad es fundamental, tienen que ver en mi una artista que a la vez es profesora y que comparte con ellos esta doble identidad en un trabajo colaborativo).

Como aspecto transversal trabajamos el problema del mal, iniciando con el asunto de los miedos, observando cómo los cuentos de hadas ayudan a acercarnos a la integración de los valores. Un educador es un ser ético y que comparte y ayuda a reflexionar sobre la vida.

\section{El proceso. La agenda de la maestra9}

1aㅡ Clase

Me presento y presento la dinámica de clase. Horario abierto, iniciamos a las 15:30 y terminamos a las 20:30, pero son ellos los que tienen que controlar para permanecer en clase tres horas y media que es su obligación académica y por lo tanto organizar y controlar su tiempo ${ }^{10}$. Propongo responsabilidad y libertad como forma de enfocar la clase (quien así lo desee y pueda podrá quedarse las cinco horas). Siempre iniciaremos y terminaremos con asamblea.

Trabajamos contándonos por parejas un relato onírico que consideremos nuestro peor sueño, primero una persona y luego la otra. Después definimos un miedo que nos transmitió el sueño de la compañera. Los escribimos en la pizarra.

9 Desarrollo aquí lo que pasó con los estudiantes siguiendo el itinerario trazado por nuestras clases y apoyándome en los apuntes de mi cuaderno de bitácoras.

10 Según el plan de Bolonia, la clase se divide en práctica y teórica. La teórica la disfruta el grupo completo y para la práctica en principio partimos el grupo. Pero de hace varios años planteo como innovación docente que ellos se regulen el tiempo, entendiendo que en Educación Artística, práctica y teoría van de la mano, y no divido el grupo. La autorregulación de su tiempo como estudiantes supone ya en sí un compromiso ético y una reflexión acerca de las elecciones en la vida, estar o ausentarse, y los imperativos, externos o internos. 
Buscamos un antídoto a ese miedo.

Lo compartimos, primero miedos, luego antídotos.

Les enseño la página y el blog de clase, la próxima semana abriremos los blogs de grupo que es un lugar donde irán reflejando sus reflexiones y memoria de curso, sus procesos de investigación en la asignatura y que será parte de la evaluación junto a un vídeo individual final.

Les enseño la performance posbolonia. El vídeo genérico y el vídeo final de la transformación del posbolonio.

Hacemos una relajación siguiendo el sistema de EMDR con golpecitos de fondo.

$2^{a}$ Clase

Se habla del colegio y el niño que se ha suicidado, afrontamos el asunto de la psicopatología. Les pongo un vídeo del profesor y psicólogo Iñaki Piñuel para abordar este tema.

Hablamos de los abrazos, del poder de los abrazos y de cómo es algo cultural. Menciono el trabajo de la artista y profesora Mónica Aranegui, vemos su vídeo performáticode abrazos.

Hablamos de performance, les pongo un vídeo de Marina Abramovich.

También nos acercamos al trabajo performático de Nieves Correa y su pareja Abel Loureda.

Les explico el taller de la amenaza que realizamos en un aula de doctorado y la experiencia de Inmaculada González que era alumna en ese programa y que como maestra, lo aplicó con sus niños de infantil (4-5 años) en un formato que llamaron el taller del miedo.

Se decide hacer un atrapa miedos en la siguiente clase. 
Hoy construimos el atrapamiedos. Antes de esta clase hemos:

- Reflexionado durante esta semana acerca de nuestros miedos, a través de escritos e imágenes (dibujando, tomando fotos...).

- Pensar en el miedo que nos transmitió el peor sueño de nuestro compañero y en el antídoto que inventamos para acabar con ese miedo.

- Este proceso de incubación acerca de nuestros miedos nos ayudará a decidir los materiales que llevaremos al aula de tal forma que nuestro atrapa-miedos sea eficaz para nosotros, y que verdaderamente nos identifique.

- Llevar al aula todos los materiales que podamos necesitar para desarrollar el atrapa-miedos.

Cuando llegamos les animo a hacer una relajación, utilizo la técnica del humo negro que dejamos ir y la luz que nos llena con cada nueva inspiración ${ }^{11}$.

Comento que casi todos los atrapamiedos tienen una forma de mandala, explico que es una figura universal, que tiene que ver con el centro y la periferia. Es una forma que se utiliza para relajación.

La clase se desarrolla como taller. Les pongo unos fragmentos de la película "El baile" de Ettore Scola reflexionando sobre las caracterizaciones e identidades.

Alguien comentó sobre la posibilidad de disfrazarnos porque llega Carnaval y yo les enseñé el trabajo de los disfraces cotidianos que hemos hecho otros años (en esa experiencia vamos diciendo situaciones diversas para las que nos vestimos de tal o cual manera y a partir de ahí confeccionamos una lista que luego se sortea y las

11 Es una técnica de meditación budista que transforma y produce claridad mental. 
personas se visten para esas ocasiones y de esa manera observamos que todo en esta vida es disfraz).

Les mostré con ayuda del powerpoint de sueños, la teoría psicoanalítica de que tenemos "la persona o máscara social”, siguiendo las teorías de Carl Gustav Jung.

En una tormenta de ideas les pregunto qué es un disfraz y según esa reflexión, decidimos que en la siguiente clase vendremos disfrazados, si bien será algo muy sutil, que no parezca disfraz, pero que lo sea.

En la incubación de ese proceso de colocarse otra identidad, ponerse en otra piel, dejar salir algo que refuerza nuestro ser de niño, colocarse algo que normalmente no lo hacemos etc... les animo en la incubación a hacerlo días antes, no el mismo día de la clase, sino integrarlo con anterioridad, para que se ubique en cada uno y adquiera "normalidad".

La idea es que lo presenten y lo expongan en clase, también que interactuemos y reflexionemos entre todos.

$4^{\text {a }}$ Clase

Quedamos que vamos a empezar con el ritual de mostrar el ponerse en otra piel, van subiendo a la tarima de la clase, se dejan ver y miran a los compañeros, se comenta y el clima es muy emotivo y de gran confianza, luego la persona se expresa. Ha sido muy emocionante ${ }^{12}$.

12 Aparentemente no iban disfrazados. La "procesión iba por dentro". Por ejemplo, uno de los estudiantes maquilló su cara como si le hubieran golpeado fuertemente y leyó un poema a su padre. Dos estudiantes llevaban sendas barrigas de embarazos muy avanzados que habían paseado por el tren y la universidad. Otra, íntegramente vestida de negro habló de su fortaleza y las ocho operaciones de corazón que llevaba su cuerpo... 
En esta clase Aída Miró vino también a compartir su experiencia como artista de Butoh y de Clown.

Hemos terminado con una limpieza de aura. Visionando también un vídeo de Enric Corberá sobre genealogía.

5 Clase

Vamos a realizar un taller de mandalas de chocolate, para ello por grupos traemos: obleas de las que se compran en panaderías o grandes superficies, papel de cocina o servilletas para poner en las mesas y colocar encima las obleas. Chocolate
Figura 4 - Para el ejercicio de llevar un disfraz que no lo parezca, dos de mies estudiantes llevan embarazos avanzados que pasearon por el tren, por la universidad y que normalizaron en sus vidas

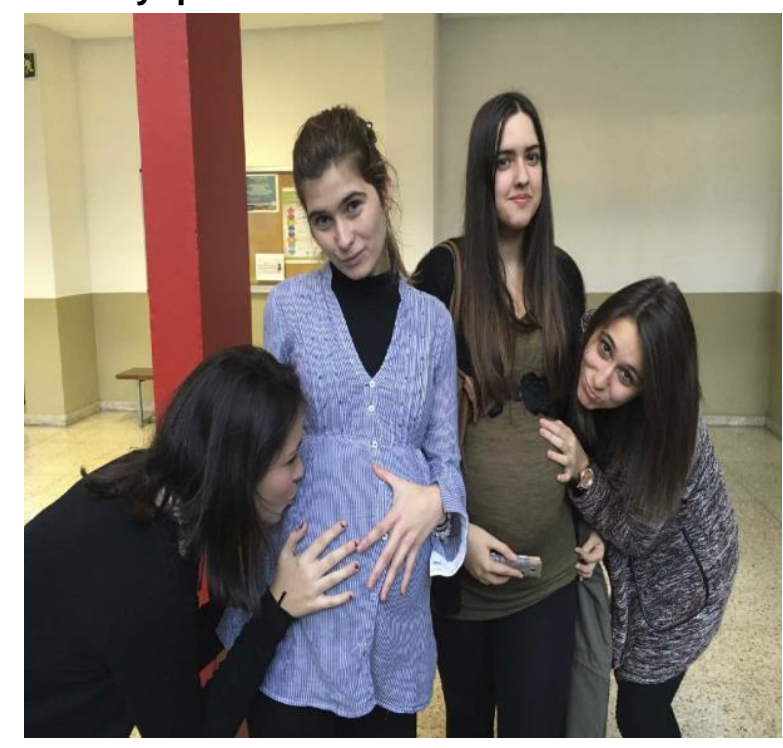

Fuente: Archivo de la autora

líquido que mejor si es negro y con no mucho azúcar. Pinceles. Platos de plástico. Los estudiantes suelen traer otros "complementos" para decorar los mandalas (lacasitos, leche condensada, chocolate en virutas etc.) hay que recordar que la idea es poder comérselo, si la cosa está muy cargada de azúcar no será tan sano de digerir, pero tampoco es obligado comerlo.

Empiezo la clase explicando la teoría del mandala según la psicología de las profundidades, como centro psíquico y con la explicación de las capas de vulnerabilidad y protección de Krishnananda. Luego se ponen a hacer los mandalas. Al final de la clase hablamos de somatizaciones, de vomitar o no vomitar... visionamos un documental de la Abuela Margarita, hablamos un poco sobre psicomagia y vemos un trabajo de Alejandro Jodorowsky y una estudiante habla de danza contemporánea, vemos un vídeo de Cunningham.

\section{$6^{\text {a }}$ Clase}

Viene Daniella Zanellato y hablamos de la Educación Artística en Brasil, de la labor de Ana Mae Barbosa que fue alumna de Paulo Freire, del trabajo en artes a 
partir de la triada: producción, apreciación estética, contexto social y crítica. También aprovechamos para mencionar el cuerpo como mediador y símbolo, lateralidad izquierda y derecha, al ver que algunas personas se habían herido sincrónicamente en esa semana.

Vemos el vídeo de la performance "Camisa amarela vira a chitao" realizada junto a Henrique Lima y en la que se ve a Ana Mae Barbosa, sirve para reflexionar sobre la cuestión de género. Daniella en otra clase me dirá luego que buscó la letra de la canción de Gal Costa que se utilizó en esta performance y tomó conciencia de lo machista que es y de cómo usa el argot.

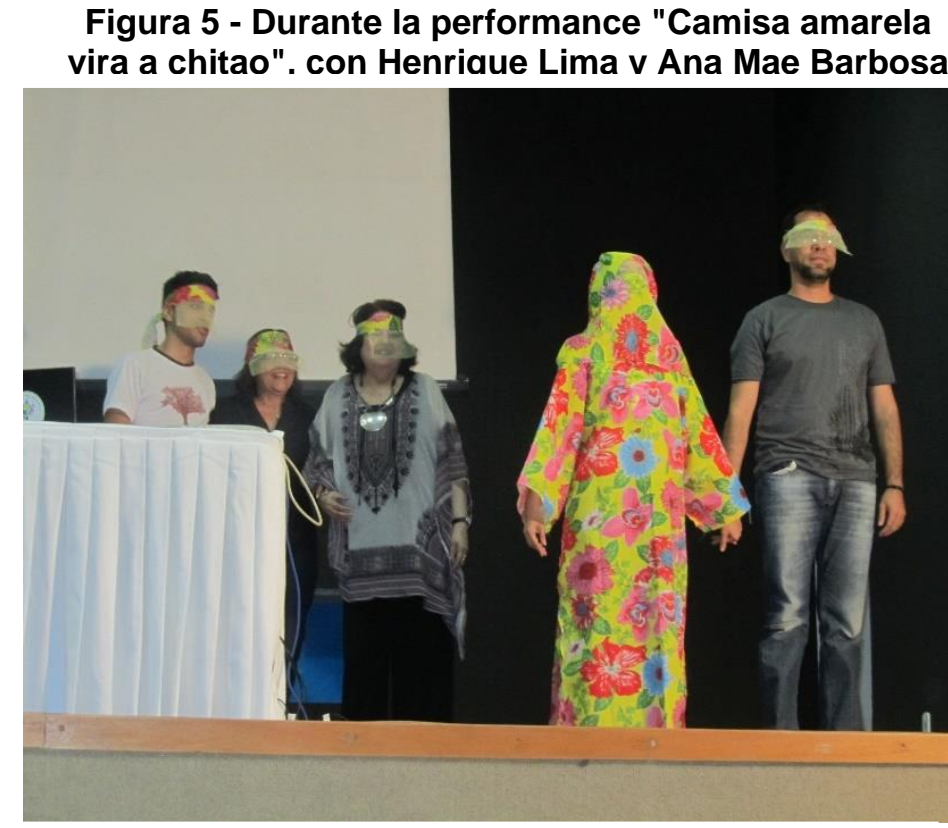

Fuente: Archivo de la autora

Hoy realizaremos varios dibujos, el primero es libre en un papel en grupo. El segundo es libre también, pero usando los cascos de música. Un tercer dibujo se hace con los ojos tapados con un pañuelo.

Terminamos viendo la película "Blancanieves" de Pablo Berger, que nos dará pie para comenzar ya a trabajar con este cuento. Comentan que les ha sido muy dura, que es una historia muy fuerte, tremenda, con ese final, les llama la atención el final. También reflexionamos sobre la reacción de Blancanieves ante la aparición de la madrastra con la manzana. Yo vi claramente un fenómeno de estrés post traumático, bloqueo, pues no la reconoce.

\section{$7^{a}$ Clase}

A partir de la película que ya hemos visto de Pablo Berger, deberemos:

Observar los elementos simbólicos que aparecen. 
Incubar la historia, buscar identificación con alguno-algunos de los personajes, situaciones personales vividas. Llevarlo por escrito e incluso si tenemos alguna imagen que nos haya traído el recuerdo viendo la película, pues traer esa imagen.

Hablamos de la película, se mencionan las posibilidades de identificación y se plantean posibilidades de trabajo a partir de la película. Se llega al final a la conclusión de hacer un proyecto de película colectiva.

Seguimos el taller de dibujo colectivo. Se juega creativamente, se atan las manos entre ellos, dibujan con la mano que no suelen dibujar...

Se hace el dibujo con ojos cerrados, luego con ojos cerrados y música, luego atando la mano y luego atando la mano con música, se hacen al final seis dibujos. Comentan que con música es mucho más sencillo concentrarse y que con la mano que normalmente no se usa llega un momento que es agradable porque fluye muy bien.

\section{$8^{\mathrm{a}}$ Clase}

Iniciando el proyecto de versionar el cuento de Blancanieves, buscaremos en los diferentes grupos adaptaciones del cuento, en formato fundamentalmente vídeo o película.

Leeremos el cuento de los hermanos Grimm antes del jueves.

Para poder versionar hay que conocer bien el cuento y sus elementos simbólicos.

Hablamos de los puntos que se encontraron interesantes en el cuento. Se vio el asunto de los objetos malditos para matar a Blancanieves. Por grupos indicaron puntos que consideraban importantes de cara a la nueva versión del cuento.

Se vio que había una tendencia transgresora frente a otra más mágica o edulcorada. 
Al inicio de la clase conté que soñé una canción de George Brassens "J'ai rendez -vous avec vous", que había acontecido luego un hecho sincrónico y no querría que fuera la cita de la bruja, así que hicimos un baile para conjurarlo. Comentamos que parecía el baile de Blancanieves con los enanitos, a Daniella le recordaban bailes que se bailan en Brasil para las fiestas de junio.

La gente estaba tímida, pero bailó casi todo el mundo.

Luego en la segunda parte de la clase comenzamos a analizar dibujos de niños. Vimos el tema del estereotipo emocional que se refleja en los dibujos y salió el controvertido asunto del color rosa. Podríamos quizás hacer un día del color rosa, venir vestidos de ese color etc.

\section{$9^{a}$ Clase}

Hoy presentamos los colores que asociamos a los personajes de Blancanieves.

Hemos incubado un personaje del cuento y lo hemos asociado a una gama de color y venimos ese día vestidos de esa gama de colores, todo lo posible, es decir de cabeza a pies.

\section{Figura 6 - Los príncipes}

Llevamos también un objeto que nos atraiga por su color fundamentalmente y que consideremos podría ser un antídoto al peine envenenado, las joyas emponzoñadas, las flores mortíferas o la manzana fatal, según las versiones del cuento.

Observamos coincidencias en la asociación de personajes

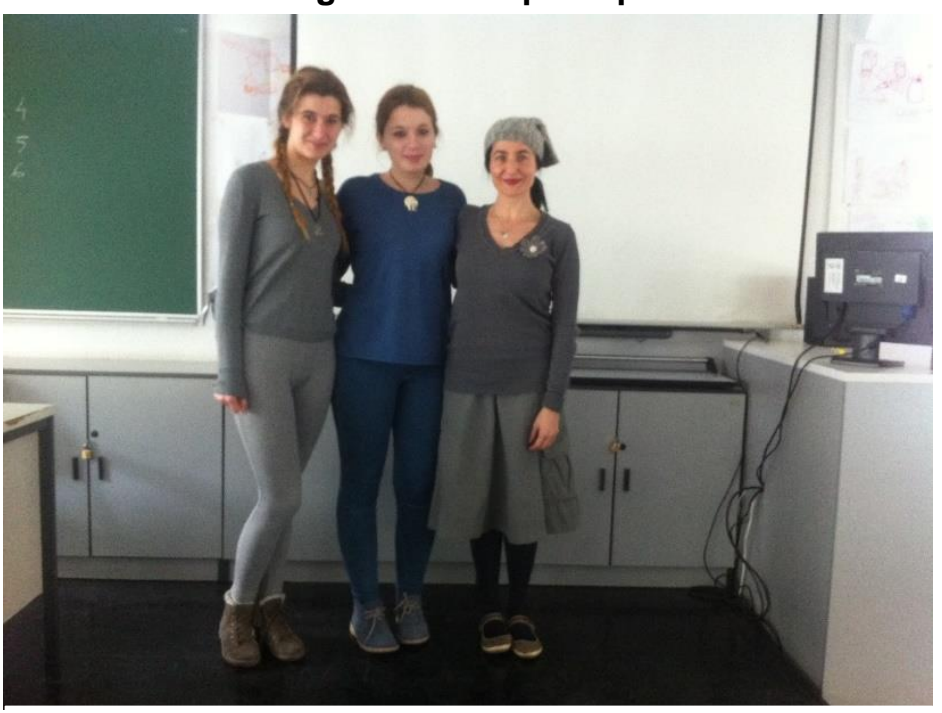

Fuente: Archivo de la autora y/colores y también compartimos esos objetos salvíficos. En la segunda parte de la clase hacemos un trabajo sobre el niño interior, visualizándolo. 


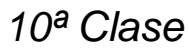

Trabajamos por grupos sobre el cuento de Blancanieves, buscamos puntos en común para el guión, para el mensaje, la estructura, la estética... y definimos la excursión a Sigüenza para el 21 de abril.

Trabajamos sobre dibujo infantil con producciones de niños de 5 años y luego de 8 años, reflexionamos sobre las ocasiones en que el dibujo de los niños nos muestra situaciones de maltrato.

$11^{a}$ Clase

Trabajamos sobre la errancia para terminar de decidir cómo enfocarla y llegamos a acuerdos acerca de cómo vamos a afrontar esta salida performática. Luego realizamos la actividad de mirarnos a los ojos. Cambiamos y pasamos por varios compañeros, al final se introduce una propuesta en la que al mirar a los ojos imaginamos sobre la vida del otro.

Luego realizamos una práctica de pintura con dedos.

$12^{a}$ Clase

Salida errancia Figura 7 - Brujas y Blancanieves, terminada la errancia arquetípica en Sigüenza arquetípica a Sigüenza. Habíamos acordado que cada cual elegiría si iría como Blancanieves 0 como Bruja. Decidiría un color para vestirse de la cabeza a los pies, tanto Blancanieves como Brujas. Las Blancanieves llevan flores en el pelo, las Brujas llevan pañuelos, ese es el código que

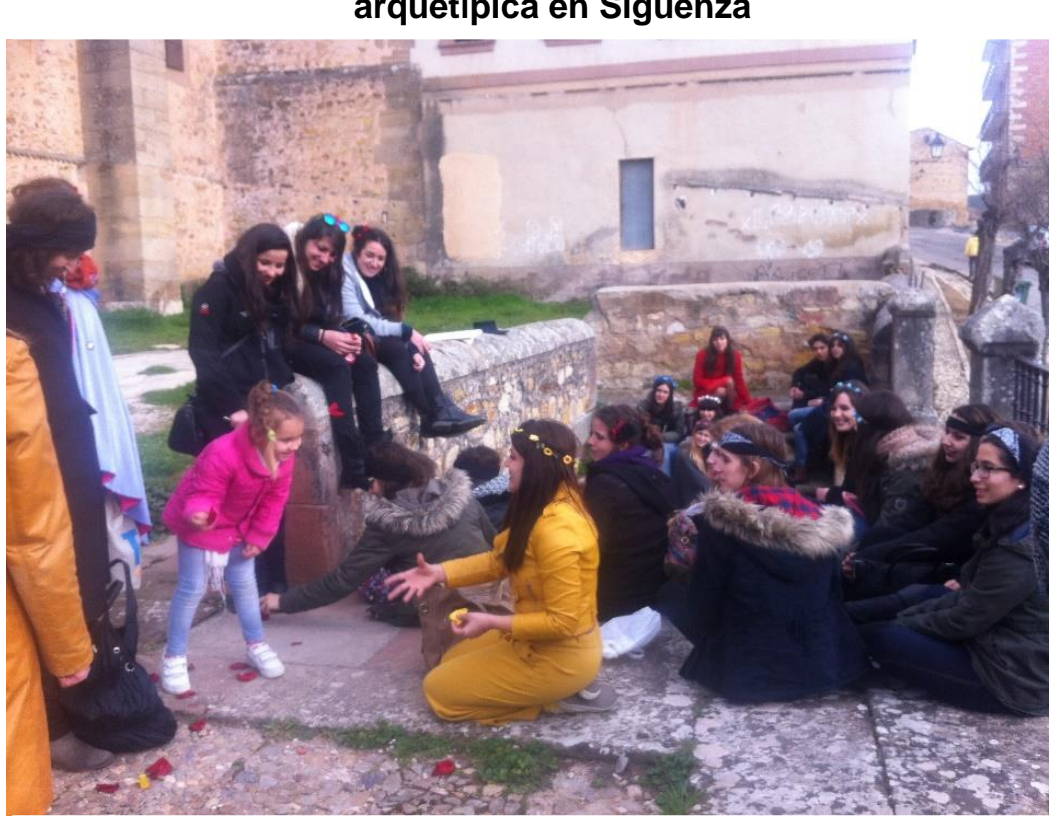

Fuente: Archivo de la autora 
diferencia. En el autobús se sortearon las Blancanieves que serían perseguidas por las Brujas. Podrían alcanzarlas y soltarlas hasta tres veces que sería la captura definitiva. Las Blancanieves no saben quién es su bruja. Observamos que sincrónicamente tenemos 16 Blancanieves, 16 Brujas y 16 personas que dijeron que participarían en la errancia, y al final no vinieron.

Por mi parte en esta errancia desarrollé una performance en que transmitía el fuego, vistiendo unas "alas de mala", y encarnando el arquetipo del dragón.

$13^{a}$ Clase

Compartimos la experiencia de Sigüenza. Intercambiamos impresiones.

Tiempo de pintura colectiva a partir de las emociones mientras se incuba el vídeo final que versione Blancanieves.

Una estudiante se dio cuenta de queen las diferentes versiones de Blancanieves, este personaje tiene los mismos colores que las cartas del Tarot de Marsella. Vemos la carta la "Torre de la Destrucción" que es el arcano número 16 y que marcó la sincronía del viaje a Sigüenza.

$14^{a}$ Clase

Seguimos con la

Figura 8 - Preparando la performance final. Todos con una camiseta blanca, vaqueros y unaprenda negra encima.

versión de Blancanieves, sale como solución realizar una experiencia performática a partir de la idea de una de las estudiantes sobre los grupos de adictos. Quien así lo decidiera, se diría Blan canieves y aparecería vestida con una camiseta blanca, en el círculo que dibujarían las sillas con las otras quince Brujas vestidas Contando las manzanas

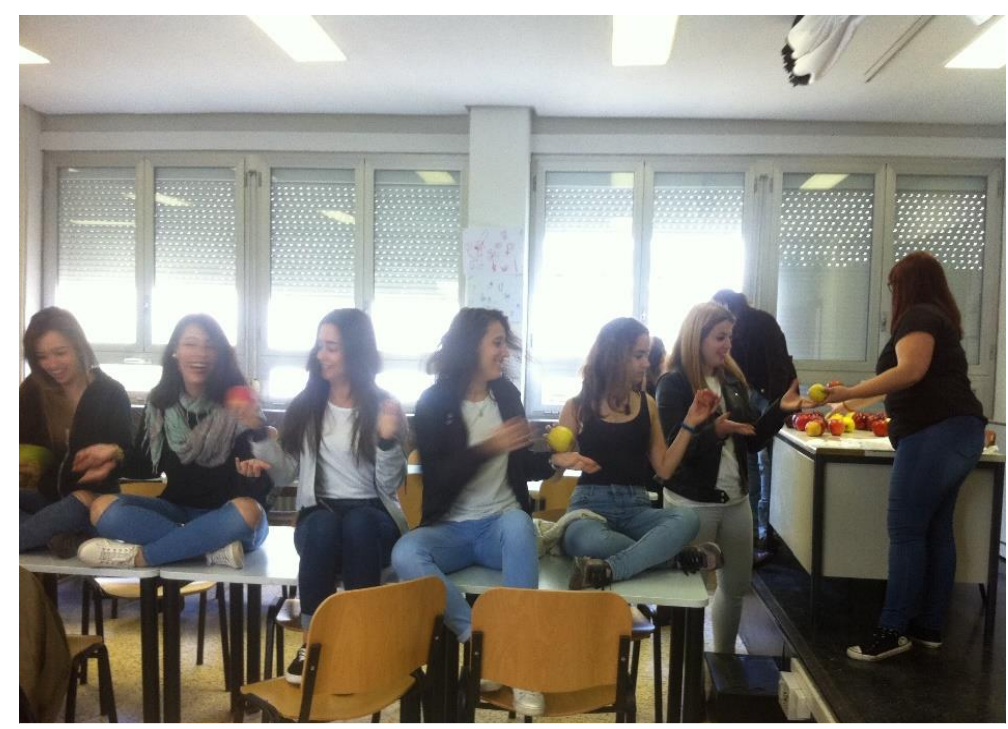

Fuente: Archivo de la autora

PÉREZ CAMARERO, Pilar. O Ensino da Arte como espaço para a reflexão ética. Enfrentar o problema do 511 mal através de uma experiência em sala de aula: Branca de Neve e os predadores internos/externos da psique. Revista GEARTE, Porto Alegre, v. 5, n. 3, p. 492-515, set./dez. 2018.

Disponível em: http://seer.ufrgs.br/gearte 
con una prenda negra (decidimos que era necesario utilizar el número 16 que apareció en la errancia a Sigüenza de una forma tan evidente). Blancanieves se pondría de pie, compartiría en voz alta algo que expresara su debilidad (adicción). Luego pasaría frente a cada Bruja que también le participaría un problema personal o defecto en voz alta (adicción), dándole a morder su manzana y entregándole su prenda negra. Al final del recorrido de las 15 Brujas, Blancanieves lleva encima todas las prendas negras mientras que las Brujas restan con las camisetas blancas que llevaban debajo y habrá comido de 15 manzanas.

Terminamos con dibujo infantil.

\section{$15^{\text {a }}$ Clase}

Hoy realizamos la performance colectiva que versiona Blancanieves. Traemos una camiseta blanca y otra negra. Pantalones vaqueros y un mínimo de dos manzanas por persona.

Participan cinco Blancanieves y quince brujas en cada vuelta performática (algunas personas repiten rueda). Los estudiantes se van turnando. La participación es libre en cada vuelta. Al final Figura 9 - Las manzanas listas para la performance final se quedan las personas necesarias para poder hacer la performance. Nos encontramos con que el número de manzanas que tenemos y el de Blancanieves y Brujas coinciden exactamente. Quince Brujas por cinco Blancanieves. Pido que se marchen los que no van a participar en el vídeo. Al

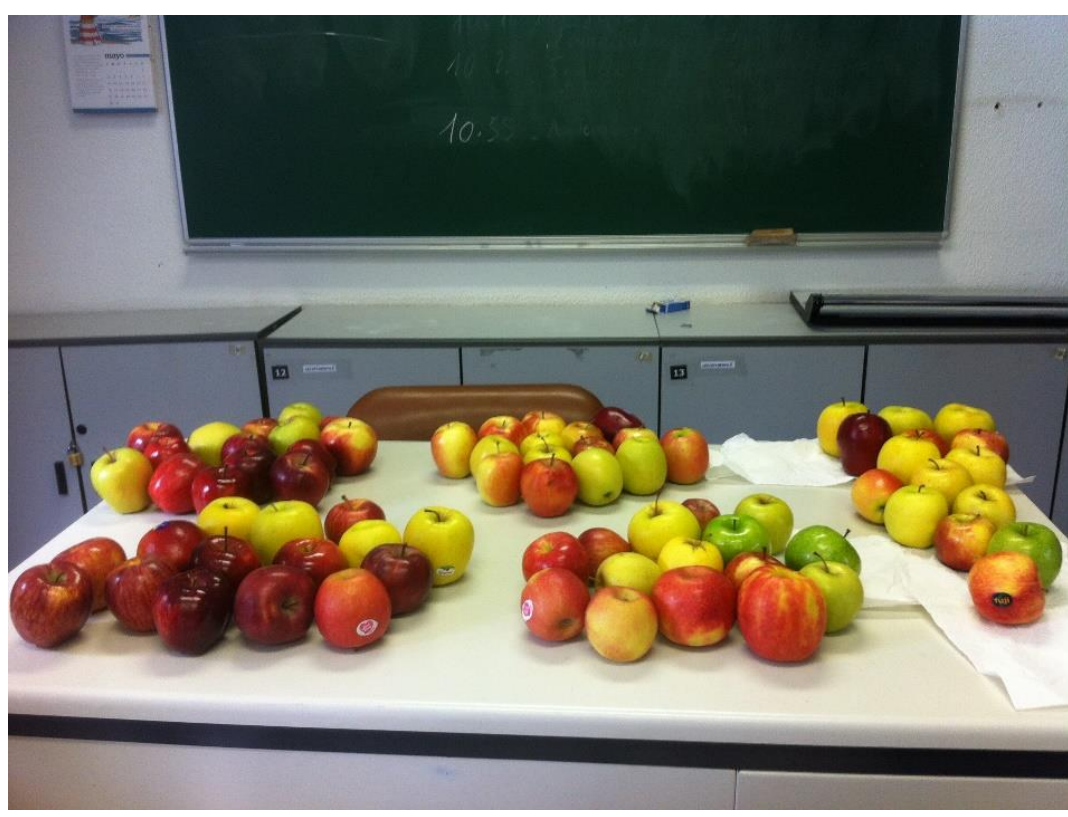

Fuente: Archivo de la autora tratarse de una performance el ambiente es particular, ritual, sagrado, no es posible 
permanecer como espectador. Se quedan dos personas a grabar. Yo decido colocarme un jersey rojo para construir así la triada de los tres colores alquímicos. Me pongo detrás de la silla de la persona que es Blancanieves, allí permanezco todo el tiempo. La reacción de cada Blancanieves es diferente, una sale a vomitar, otra llora, otra arranca las prendas negras al final con evidente estrés, hay una que parece actuar y tenemos también un chico que es Blancanieves. Alguna persona repite también como Bruja en las diferentes rondas.

$16^{a}$ Clase

Se exponen los vídeos individuales finales de los estudiantes, compartimos y reflexionamos.

\section{Resultados y Discusión. Conclusiones.}

Estoy maravillada y agradecida con lo que ha pasado en esta experiencia, es sorprendente que también el número de clases que hemos compartido juntos sean 16. El número 16 acompañando con su ritmo desde la salida arquetípica a Sigüenza, parece demostrar que cuando lo simbólico y lo inconsciente se movilizan todo puede pasar. Trabajar con los cuentos de hadas puede ser un tanto temerario, se trata de entrar en un registro que habla directamente a nuestra psique, a una parte muy primigenia de la misma. Los arquetipos se ponen en marcha y adquieren autonomía.

A través de las anotaciones que he rescatado de mi diario de clase se ve cómo el proceso en que trabajamos el cuento se fue produciendo a la vez que entrábamos (ya desde la primera clase) en el problema del mal al tratar los miedos y poco después al abordar el suicidio escolar, el bullying y la psicopatía.

Me parece muy interesante que el versionado del cuento, finalmente tomó la forma de una performance que grabamos y donde el proceso fue fundamental, todo aquello que ocurrió nos transformó a todos, y no teníamos un guión de lo que iba a pasar.

Seguramente la errancia arquetípica ayudó mucho para entrar en una dinámica en que el problema del cuento se viviera de una forma tan personal por los 
estudiantes, pero también las anteriores dinámicas, en que poco a poco, fuimos comprendiendo la fuerza del universo simbólico y acercándonos al cuento a través de sus personajes y arquetipos con diferentes ejercicios de introspección.

Hemos incubado y reflexionado sobre el mal a partir de la experiencia, de la práctica artística, del viaje hacia dentro y hemos aprendido empatía, dejando el juicio a un lado. Hemos integrado la polaridad, la dualidad y hemos avanzado en autoconocimiento.

En cualquier caso, esto no habría pasado ni se habría desarrollado de esta forma con otro grupo, los estudiantes que participaron crearon las sinergias y estoy agradecida sobre todo a ellos por haber hecho posible algo tan especial e inolvidable en mi carrera como maestra.

\section{Referencias}

ARENDT, Hannah. Eichmann en Jerusalén. Barcelona: Debolsillo, 2017.

CZIFFRA, Claire-Lucie. Les relations perverses: si le pervers m'était conté. Paris: Ed. Eyrolles, 2012. FRANZ, Marie-Louise von. L'ombre et le mal dans les contes de fées. Paris: Éditions J. Renard, 1990.

HARE, Robert. Sin conciencia: el inquietante mundo de los psicópatas que nos rodean. Nueva York: The Guildford Press, 1993.

JUNG, Carl Gustav. Respuesta a Job. México DF: Fondo de Cultura Económica, 2006.

KRISHNANANDA. De la codependencia a la libertad: cara a cara con el miedo. Madrid: Editorial Gulaab, 2007.

LAO TSÉ. Tao Te King: el libro del Tao. Mallorca: Editorial José J. de Olañeta, 2016.

MILLER, Alice. El drama del niño dotado y la búsqueda del verdadero yo. Barcelona: Ensayo Tusquets, 2016.

PIÑUEL, Iñaki. Amor Zero: cómo sobrevivir a los amores psicopáticos. Buenos Aires: Editorial Sb, 2015. RACAMIER, Paul-Claude. Les perversions narcissiques. Paris: Payot, 2012.

\section{Vídeos}

PÉREZ, Pilar (Coord.). Baile para conjurar a la bruja. 2016. Disponible en: <https://www.youtube.com/watch?v=KSKjpXH8॥Q>. Acceso en: 19 dez. 2018.

PÉREZ, Pilar (Coord.). Blancanieves y las 16 manzanas brujas. 2016. Disponible en: <https://www.youtube.com/watch?v=su9zy_WYtxc\&t=169s>. Acceso en: 19 dez. 2018.

PÉREZ, Pilar. Coord. Blancanieves y las 16 manzanas brujas. Trailer. 2016. Disponible en: <https://www.youtube.com/watch?v=0i2EjbkLtnQ>. Acceso en: 19 dez. 2018.

\section{Blog de clase}

PÉREZ, Pilar. 2009-2018. Disponible en: <http://educacionartistica.pilarperez.com/>. Acesso en: 19 dez. 2018. 


\section{Pilar Pérez Camarero}

Doctora en Bellas Artes por la Universidad Complutense de Madrid (UCM) y Experta en Educación Artística por la UCM. Posgraduada en Psicoanálisis Analítico por la Universidad Ramón Llull de Barcelona. Profesora Titular en el Departamento de Educación Artística, Plástica y Visual. Mi experiencia como docente comienza en el tiempo de mi formación doctoral en el Departamento de Bellas Artes de la UCM, y en diversas estancias en universidades de Latinoamérica (Cuba, México y Brasil). Después he desarrollado mi trabajo en la Universidad Autónoma de Madrid (UAM) en formación de profesores desde 1999, en el Doctorado de Creatividad Aplicada y en el de Arte terapia en contextos sociales diversos, ahora Máster de Arte Terapia y Título Propio de Creatividad Aplicada.

Email: p.perez@uam.es

Currículo: https://www.ucm.es/data/cont/media/www/pag-53258/EDIT\%20cv\%20pperz\%20web.pdf

Recebido em 15 de novembro de 2018 Aceito em 10 de dezembro de 2018 